Phạm Nguyễn Tố Như, Lâm Thị Mỹ [2] tử vong là khổng đáp ứng với bơm Surfactant và nhiễm trùng sơ sinh. Nguyễn Viết Đồng [6], tử vong do suy hô hấp (50\%) và xuất huyết phổi $(33,3 \%)$, nhiễm trùng huyết $6,7 \%$.

Chúng tôi, 46 ca thở máy không xâm nhập NCPAP/NIPPV với thời gian trung vị là 6 ngày. Theo Nguyễn Viết Đồng [6] là 5,1 ngày. Các biến chứng gôm: tràn khí màng phổi $(5,3 \%)$, xuất huyết phổi $(5,3 \%)$ và hạ huyết áp hệ thống $(15,8 \%)$ tương tự kết quả của một số nghiên cứu trong nước khác ${ }^{[6][2] . ~}$

\section{KẾT LUÂ̂N}

Điêu trị Surfactant thay thế ở trẻ sơ sinh non tháng bị bệnh màng trong tại Bệnh viện Sản-Nhi Quảng Ngã̃i đem lại hiệu quả lâm sàng rõ rệt, giảm nhu câu Oxy sau bơm thuốc 1 giờ, $X-$ Quang phổi cải thiện $96,5 \%$ sau 6 giờ bơm thuốc. Bệnh có liên quan đến giới tính nam.

\section{TÀI LIÊU THAM KHẢO}

1. Pham Nguyễn Tố Nhứ, Lâm Thị Mỹ (2010), "Mổ tả kết quả điều trị bênh màng trong ở tré sanh non bằng Surfactant qua kỹ thuật INSURE", Tạp chí $Y$ học thành phố Hồ Chí Minh, 1(14)', tr.155-161.
2. Trân Thị Bích Phượng, Trân Tôn Nữ Anh Ty (2012), "Đánh giá hiệu quả điều trị Surfactant trong điêu trị bệnh màng trong ở trẻ sinh non tại khoa hồi sức cấp cứu Bệnh viện Nhi Đồng Nai", Đề tài cấp tỉnh năm 2012.

3. Trân Thị Thủy, Ngô Thị Xuân (2017), "Kết quả phương pháp INSURE trong điều trị hội chứng suy hô hấp ở trẻ đẻ non tại Bệnh viện Sản Nhi Bắc Ninh năm 2017 ", Tap chí Khoa học ĐHQGHN: Khoa hoc Y Dước, 33(2), tr.106-114.

4. Nakhshab $M$, Tajbakhsh $M$, Khani $S$, et al (2015), "Comparison of the effect of Surfactant administration during nasal continuous positive airway pressure with that of nasal continuous positive airway pressure alone on complications of respiratory distress syndrome: a randomized controlled study", Pediatrics \& Neonatology, 56 (2), pp. 88-94.

5. Nguyê̂n Viết Đồng, và cs (2018). Nghiên cứu điểu trị bệnh màng trong ở trẻ đẻ non bằng liệu pháp Surfactant tại Khoa Nhi - Bệnh viện đa khóa tỉnh Hà Tỉnh.

6. Fujiwara T, Chida S, Watabe Y, et al (1980), "Artificial Surfactant therapy in hyaline-membrane disease", The Lancet, 315 (8159), pp.55-59.

7. Ramathan R, Rsmussen MR, Gerstmann D, et al (2004) "A randomized, multicenter masked comparison trial of Curosuff versus Survanta in the treatment of respiratory distress syndrome in preterm infant", AJP, 21(3), pp.109- 119.

\title{
KẾT QUẢ BAN ĐẦU CỦA PHẪU THUÂTT ĐIỀU TRI LỖ HOÀNG ĐIỂM DO CHẤN THƯƠNG ĐỤNG DẬP NHÃN CẦU
}

\author{
Nguyễn Minh Thi ${ }^{1}$, Đỗ Như Hơn' ${ }^{1}$, \\ Thẩm Trương Khánh Vân ${ }^{2}$, Nguyễn Thái Đạt ${ }^{2}$
}

\section{TÓM TẮT}

Lỗ hoàng điểm do chấn thương đụng dập nhãn cầu là một bệnh lý nặng, ảnh hưởng nghiêm trọng đến chức năng thị giác. Cho đến nay, phâuu thuật cắt dich kính, bóc màng ngăn trong, độn khí nở nội nhãn vẫn được áp dụng cho những trường hợp lỗ hoàng điểm chấn thưởng không tự đóng và mang đến kễt quả khả quan. Tuy nhiên những báo cáo về kết quả điều trị lô̂́ hoàng điểm chấn thương còn lẻ tẻ và chủ yếu được thực hiện trên các nhóm bệnh nhân nhỏ. Mục tiêu nghiên cứu nhằm mô tả một số kết quả ban đầu của phẫu thuật điều trị lỗ hoàng điểm do chấn thương đụng dập nhãn cầu. Nghiên cứu mô tả được tiến hành trên 33 mắt có lỗ hoàng điểm do chẩn

1 Trường Đại học Y Hà nội

²Bệnh viện Mắt Trung ương

Chịu trách nhiệm chính: Nguyễn Minh Thi

Email: nguyenminhthi.vnio@gmail.com

Ngày nhận bài: 3.3.2021

Ngày phản biên khoa học: 23.4.2021

Ngày duyệt bài: 4.5.2021 thương đụng dập nhãn câu. Kết quả cho thây $81,8 \%$ nhóm nghiên cứu thành công đóng lỗ hoàng điểm sau một đễn hai lần phẫu thuật. 57,6\% các trưỡng hợp đóng lỗ hoàng điểm type 1 và $24,2 \%$ đóng lố hoàng điểm type 2. Có $27,3 \%$ tổng số bệnh nhân cần đến phẫu thuât lần hai sau phẩu thuật lần đầu tiên lỗ hoàng điểm không đóng. Trong nhóm này, tỉ lệ đóng lố hoàng điểm chỉ đạt $44,44 \%$ với tỉ lệ đóng lố hoàng điểm type 1 sau mổ rất thấp chỉ đạt $11,11 \%$. Sau phẫu thuật 3 tháng, 45,5\% số bệnh nhân có cải thiện thị lực tự 2 dòng Snellen trở lên. Chiêu dày trung tâm hoàng điểm và vùng ellipsoid sau phẫu thuật giảm nhẹ so với trước phẫu thuật, không có ý nghĩa thống kê. Với những trường hợp đóng lỗ hoàng điểm type 2 sau phẫu thuật, kích thước đáy lỗ hoàng điểm có thu hẹp so với trước phẫu thuật $(p<0,05)$.

Tư khóa: Lố hoàng điểm, chấn thương đụng dập nhãn cầu

\section{SUMMARY \\ THE EARLY RESULT FOR TREATMENT OF TRAUMATIC MACULAR HOLE DUE TO BLUNT TRAUMA}


Traumatic macular hole due to blunt trauma is a serious condition that reduces visual acuity significantly. The purpose of this study is to describe some early outcomes of surgical treatment for traumatic macula hole due to blunt trauma. This descriptive study was conducted on 33 eyes of 33 patients with macular hole due to blunt trauma. The macular hole is successfully closed in $81.8 \%$ of the research group after one or two operations. $57.6 \%$ of the cases is of type 1 closure and $24.2 \%$ of the cases is of type 2 closure. There are 9 patients $(27.3 \%)$ who require a second surgery after the first surgery failed to close the macular hole. Among the group of patients requiring second surgeries, the rate of closure is only $44.44 \%$. In which, the rate of type 1 closure after surgery is very low, only about $11.11 \%$. 3 months after surgery, $45.5 \%$ of patients has visual acuity more than $20 / 160.66 .7 \%$ of patients reports improvement in their visual function after surgery, $45.5 \%$ of the patients improves their vision more than 2 Snellen lines. The central subfield thickness and the ellipsoid zone decrease slightly after surgery, the difference is not statistically significant. In type 2 closure cases , the basal diameter of the hole postsurgery decreases $(p<0.05)$.

\section{I. ĐĂT VẤN ĐỀ}

Lô̂́ hoàng điểm (LHĐ) là sự mất liên tục về giải phẫu của võng mạc thần kinh cảm thụ ở vùng trung tâm của hoàng điểm, gây suy giảm nghiêm trọng chức năng thị giác. Năm 1991, Kelli và cs báo cáo những trường hợp lỗ hoàng điểm nguyên phát đâu tiên đã được điều trị thành công sau phẫu thuật cắt dịch kính, bơm khí nở nội nhãn. ${ }^{1}$ Vai trò của cắt dịch kính trong điều trị lỗ hoàng điểm chấn thương vẫn còn chưa rõ ràng do cơ chế bệnh sinh phức tạp của bệnh. Nghiên cứu của Amari và cS cũng cho thấy tỉ lệ đóng lỗ hoàng điểm chấn thương là $70 \%$ sau một phẫu thuật và $96 \%$ sau phẫu thuật lần hai. Thị lực trung bình sau mổ là 20/60 với $61 \%$ đạt thị lực từ $20 / 60$ trở lên. ${ }^{2}$ Những cải tiến về phương pháp phẫu luôn được nghiên cứu áp dụng với mục đích tăng cao tỷ lệ đóng lỗ hoàng điểm và phục hồi thị lực tốt nhất cho bệnh nhân. Chúng tôi tiến hành nghiên cứu này với muc tiêu: Mô tả môt số kết quả ban đầu sau phẫu thuật điều trị lỗ hoàng điểm chấn thương.

\section{II. ĐỐI TƯợNG VÀ PHƯƠNG PHÁP NGHIÊN CỨU}

1. Đối tượng nghiên cứu: là những bệnh nhân (BN) bị lỗ hoàng điểm do chấn thương đụng dập nhãn cầu được khám, nhập viện và điều trị phẫu thuật tại khoa chấn thương bệnh viện Mắt TW từ 01/09/2014.

Tiêu chuẩn lựa chon bênh nhân: các bênh nhân có lỗ hoàng điểm được chẩn đoán xác định trên lâm sàng và chụp cắt lớp quang học (OCT), có tiền sử chấn thương đụng dập nhãn cầu trước đó, có các triệu chứng cơ năng (nhìn mờ, nhìn méo hình...) xuất hiện sau chấn thương.

Tiêu chuẩn loaí trừ: các bênh nhân có bênh lý nặng của bán phần trước và bán phần sau nhãn cầu do chấn thương hoặc không do chấn thương gây ảnh hưởng đến quá trình thăm khám, đánh giá tình trạng võng mạc; các bệnh nhân không phối hợp trong quá trình thăm khám (do tình trạng toàn thân nặng, quá già yếu, quá bé); các bệnh nhân không đồng ý tham gia vào nghiên cứu.

\section{Phương pháp nghiên cứu}

Thiết kế nghiên cứu: nghiên cứu mô tả, tiến cứu

Mẫu nghiên cứu: nghiên cứu được tiến hành trên 33 mắt bị lố hoàng điểm do chấn thương đụng dập nhãn cầu

Phương pháp chọn mẫu: chọn mẫu chùm ca bệnh.

Phương tiện nghiên cứu: các phương tiện sẵn có phục vụ khám, theo dõi bệnh tại bệnh viện Mắt TW

Các bước tiến hành nghiên cứu: các bệnh nhân được hỏi bệnh, khám lâm sàng, khám nghiệm OCT, được phấu thuật cắt dịch kính 23G, bóc màng ngăn trong, bơm khí nở nội nhãn (SF6 hoặc C3F8). Bệnh nhân được chỉ định nằm sấp và ngồi cúi mặt trong 1 tuần đầu sau mổ. Các bệnh nhân được khám lại sau 3 tháng, ghi nhận thị lực, các triệu chứng cơ năng và thực thể, làm lại OCT.

Các biến số nghiên cứu: - Thị lực khi vào viên/ khám lại phân loai theo WHO $(<20 / 400$, 20/400-20/200, 220/160); Mức cải thiện thị lực sau phẫu thuật: giảm, không đổi, tăng

- Type đóng của lỗ hoàng điểm sau phẫu thuât chia làm 2 type $^{3}$ :

Type 1: lỗ hoàng điểm đóng hoàn toàn, không có tổn hại lớp võng mạc thần kinh cảm thụ; Type 2: Có tổn hại lớp võng mạc thần kinh cảm thụ, bờ lỗ hoàng điểm áp sát lớp biểu mô sắc tố, quầng dich dưới bờ lỗ hoàng điểm tiêu hết.

- Các thông số của LHĐ trên OCT khi vào viện/khám lại: Chiều dày võng mạc trung tâm hoàng điểm, kích thước đáy LHĐ, kích thước đỉnh LHĐ, tổn hại mối nối phần trong-phần ngoài tế bào quang thụ (vùng ellipsoid) ( $\mu \mathrm{m})$

3. Xử lý số liệu: số liệu được nhập trên chương trình SPSS 16.0

4. Đạo đức nghiên cứu: bệnh nhân tự nguyện tham gia nghiên cứu. Các thông tin cá nhân của đối tượng nghiên cứu được bảo mật và chỉ phục vụ cho mục đích nghiên cứu.

\section{KẾT QUẢ NGHIÊN CỨU}

\section{Tỷ lệ đóng lỗ hoàng điểm sau phẫu thuật}




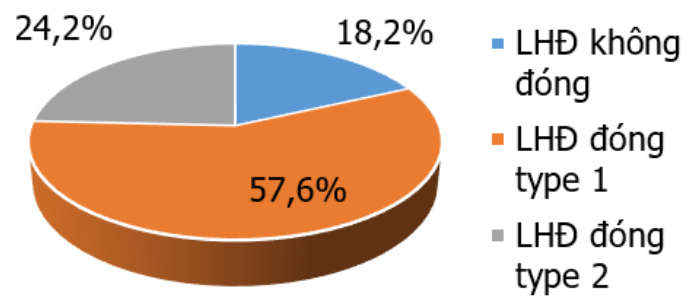

Biểu đồ 1: Tỉ lệ đóng lỗ hoàng điểm sau phẫu thuât cắt dịch kính

Trong nhóm nghiên cứu có 27 bệnh nhân chiếm $81,8 \%$ các trường hợp đóng î̃̂ hoàng điểm sau một đến hai lần phẫu thuật. Có $27,3 \%$ tổng số bệnh nhân cần đến phẫu thuật lần 2 sau phâuu thuâat lần đâu tiên thất baii.

2. Kết quả thành công về giải phẫu của lỗ hoàng điểm sau phẫu thuật

Bảng 1: Kết quả giải phẩu của lỗ hoàng điểm sau phẫu thuật cắt dịch kính

\begin{tabular}{|c|c|c|c|}
\hline Mố lần 2 & Lô hoàng điếm & $\mathbf{n}$ & $\mathbf{\%}$ \\
\hline \multirow{3}{*}{ Có ( $\mathrm{n}=9)$} & Không đóng & 5 & 55,56 \\
\cline { 2 - 4 } & Đóng type 1 & 1 & 11,11 \\
\cline { 2 - 4 } & Đóng type 2 & 3 & 33,33 \\
\hline \multirow{3}{*}{$\begin{array}{c}\text { Không } \\
(\mathrm{n}=27)\end{array}$} & Không đóng & 1 & 4,17 \\
\cline { 2 - 4 } & Đóng type 1 & 18 & 75 \\
\cline { 2 - 4 } & Đóng type 2 & 5 & 27,78 \\
\hline
\end{tabular}

Trong số các trường hợp phẩu thuật 1 lần, có $95,83 \%$ số bệnh nhân có thành công về giải phẫu đóng lỗ hoàng điểm với tỉ lệ đóng lỗ hoàng điểm type 1 cao lên đến $75 \%$. Trong nhóm phẫu thuật lần hai, tỉ lệ đóng lỗ hoàng điểm chỉ có $44,44 \%$ với $11,11 \%$ đóng LHĐ type 1.

3. Kết quả thị lực sau phẩu thuật điêu trị lỗ hoàng điểm

Bảng 2: Kêt quả thị lực ở thời điểm khám lại 3 tháng sau phẫu thuật

\begin{tabular}{|c|c|c|}
\hline Thị lực khám lại & $\mathbf{n}$ & $\mathbf{\%}$ \\
\hline$<20 / 400$ & 8 & 24,2 \\
\hline $20 / 400-20 / 200$ & 10 & 30,3 \\
\hline$\geq 20 / 160$ & 15 & 45,5 \\
\hline Chung & 33 & 100 \\
\hline
\end{tabular}

Sau phẫu thuật 3 tháng, có 45,5\% số bệnh nhân có mức thị lực từ 20/160 trở lên.

4. Mức cải thiện thị lực sau phẫu thuât điêu trị lỗ hoàng điểm. Trong nhóm nghiển cứu có đến $66,7 \%$ số bệnh nhân có cải thiện thị lực sau phẫu thuật. Có 15 bệnh nhân chiếm 45,5\% tổng số bệnh nhân có cải thiện thị lực từ 2 dòng Snellen trở lên. $6,1 \%$ nhóm nghiên cứu có thị lực giảm sau mổ và $27,3 \%$ số bệnh nhân có thị lực không thay đổi so với trước mổ

5. Khác biệt giữa thị lực khi vào viện và thị lực khám lại sau 3 tháng
Bảng 3: Khác biệt giữa thị lực khi vào viện và thị lực sau mổ 3 tháng

\begin{tabular}{|c|c|c|c|c|c|}
\hline \multirow{2}{*}{ Thị lực } & \multicolumn{2}{|c|}{$\begin{array}{c}\text { Thị lực } \\
\text { vào }\end{array}$} & \multicolumn{2}{|c|}{$\begin{array}{c}\text { Thị lực } \\
\text { khám lại }\end{array}$} & \multirow{2}{*}{ p } \\
\cline { 2 - 5 } & $\mathbf{n}$ & $\mathbf{\%}$ & $\mathbf{n}$ & $\mathbf{\%}$ & \\
\hline$<20 / 400$ & 11 & 33,3 & 8 & 24,2 & \\
\hline $20 / 400-$ & 12 & 36,4 & 10 & 30,3 & \multirow{2}{*}{0,06} \\
$20 / 200$ & & & & \\
\hline$>=20 / 160$ & 10 & 30,3 & 15 & 45,5 & \\
\hline Chung & $\mathbf{3 3}$ & $\mathbf{1 0 0}$ & $\mathbf{3 3}$ & $\mathbf{1 0 0}$ & \\
\hline
\end{tabular}

Sau phẩu thuật, tỉ lệ thị lực từ 20/160 trở lên tăng từ 30,3\% lên 45,5\%, nhóm thị lực kém hơn $20 / 400$ giảm từ 33,33\% xuống 24,2\%.

6. Sự thay đổi về chiêu dày trung tâm hoàng điểm trước và sau phẫu thuật 3 tháng

Bảng 4: Sự thay đổi chiều dày trung tâm hoàng điểm trước và sau phấu thuật

\begin{tabular}{|c|c|c|c|}
\hline $\begin{array}{c}\text { Chiều dày } \\
\text { trung tâm } \\
\text { hoàng điểm }\end{array}$ & TB \pm SD & Min-Max & p \\
\hline Trước điêu trị & $180,55 \pm 91,84$ & $24-411$ & 0 \\
\cline { 1 - 3 } Khám lại & $171,61 \pm 78,73$ & $39-354$ & \\
\hline
\end{tabular}

Chiều dày trung tâm hoàng điếm giảm nhe sau mổ với sự khác biệt không có ý nghĩa thống kề

7. Tổn hại mối nối phân trong-phân ngoài lớp tế bào quang thụ (vùng ellipsoid) trước và sau phẫu thuật 3 tháng

Bảng 5: Vùng ellipsoid trước và sau phẫu thuật 3 tháng

\begin{tabular}{|c|c|c|c|}
\hline Vùng ellipsoid & TB \pm SD & Min-max & p \\
\hline Trước điêu trị & $2316,49 \pm$ & $1079-$ & 0 \\
$(n=33)$ & 805,55 & 4038 & \\
\hline Khám lại $(n=30)$ & $2156,63 \pm$ & $251-$ & \\
\hline
\end{tabular}

Tốn hại mối nối phần trong và ngoài của lớp tế bào quang thụ sau phẫu thuật có giảm nhẹ. Tuy vậy sự khác biệt này không có ý nghĩa thống kê

8. Khác biệt về kích thước đáy lố hoàng điểm trước và sau phẫu thuật 3 tháng

Bảng 6: Khác biệt về kích thước đáy lỗ hoàng điểm trước và sau phẫu thuật

\begin{tabular}{|c|c|c|c|c|}
\hline $\begin{array}{c}\text { D đáy (LHÐ } \\
\text { đóng type }\end{array}$ & \multicolumn{2}{|c|}{ Vào $\mathbf{( n = 8 )}$} & \multicolumn{2}{|c|}{$\begin{array}{c}\text { Khám lại } \\
\text { (n=4) }\end{array}$} \\
\cline { 2 - 5 } & $\mathbf{n}$ & $\mathbf{\%}$ & $\mathbf{n}$ & $\mathbf{\%}$ \\
\hline$<500$ & 0 & 0 & 1 & 25,0 \\
\hline $500-<1000$ & 0 & 0 & 2 & 50,0 \\
\hline $1000-<2000$ & 7 & 87,5 & 1 & 25,0 \\
\hline$>=2000$ & 1 & 12,5 & 0 & 0 \\
\hline Chung & $\mathbf{8}$ & $\mathbf{1 0 0}$ & $\mathbf{4}$ & $\mathbf{1 0 0}$ \\
\hline
\end{tabular}

Với những trường hợp đóng lố hoàng điểm type 2 sau phẫu thuật, chúng tôi thấy kích thước đáy lỗ hoàng điểm thu hẹp so với trước phẫu thuật $(p<0,05)$. 


\section{BÀN LUÂ̂N}

Tỉ lệ đóng lỗ hoàng điểm nói chung sau một đến hai phẩu thuật của nhóm nghiên cứu là $81,8 \%$. Có $69,70 \%$ thành công đóng lỗ hoàng điểm sau một lần phẫu thuật. $27,3 \%$ tổng số bệnh nhân cần đến phẫu thuật lần 2 sau phẫu thuật lần đầu tiên lố hoàng điểm không đóng. Trong nhóm này, tỉ lệ đóng lố hoàng điểm sau mổ chỉ là 44,44\%. Do cơ chế bệnh sinh phức tạp và chưa được sáng tỏ của lỗ hoàng điểm chấn thương, vai trò của cắt dịch kính trong điều trị bệnh cũng chưa được khẳng định rõ ràng. Tuy nhiên, phẩu thuật cắt dịch kính, bóc màng ngăn trong, bơm khí nở nội nhãn áp dụng cho các trường hợp lố hoàng điểm chấn thương cũng cho các kết quả hồi phục giải phẫu và chức năng khá tốt. Những báo cáo về phẫu thuât cắt dich kính điều trị LHĐ chấn thương cho thây tỉ lệ thành công về giải phẫu dao động từ $45-100 \%$, trung bình là $92,5 \%{ }^{4-6}$ Tỉ lê đóng lỗ hoàng điểm sau một lần phẫu thuật là $83 \% .^{7}$ Nghiên cứu của chúng tôi có kết quả tương tự nghiên cứu của Amari và cs cho rằng tỉ lệ đóng lố hoàng điểm chấn thương sau 1 lần phẫu thuật là $70 \% .^{2}$ Nghiên cứu của Yuan và cộng sự cho tỉ lệ thành công về giải phẫu của phẫu thuật điều trị lỗ hoàng điểm chấn thương là $69 \% .^{5}$

Tỉ lệ đóng lỗ hoàng điểm type 1 nói chung của nhóm nghiên cứu là $57,6 \%$, tỉ lệ đóng lồ hoàng điểm type 2 là $24,2 \%$. Tỉ lệ đóng lố hoàng điểm type 1 trong nhóm phẫu thuật một lần lên đến $75 \%$. Trong khi đó ở nhóm bềnh nhân phải mổ lần hai, tỉ lệ này thấp hơn rất nhiều chiếm $11,11 \%$. Tî lệ này của chúng tôi thấp hơn so với một số nghiên cứu trên thế giới. Theo nghiên cứu của Chen và cộng sự trên các BN bị lỗ hoàng điểm chấn thương được cắt dịch kính cho kết quả trong $100 \%$ các trường hợp thành công về mặt giải phẫu, tỉ lệ đóng lỗ hoàng điểm type 1 được quan sát thấy ở $96 \%$ số mắt sau phấu thuật sáu tháng. ${ }^{8}$ Nghiên cứu của Ghoraba và cs trên 16 mắt lố hoàng điểm chấn thương được cắt dịch kính, có $81,2 \%$ các trường hợp đóng lỗ hoàng điểm type 1 và $18,7 \%$ số bệnh nhân có đóng lỗ hoàng điểm type $2 .^{6}$

Sau phẫu thuật 3 tháng, có $45,5 \%$ số bệnh nhân có mức thị lực từ 20/160 trở lên. Trong số này, thị lực tốt nhất đạt được là 20/30. Có 10 bệnh nhân chiếm tỉ lệ $30,3 \%$ có thị lực ở mức từ $20 / 400$ đến $20 / 200$ và $24,2 \%$ có thị lực kém dưới 20/400. Không có sự khác biệt có ý nghĩa thống kê giữa thị lực của bệnh nhân khi vào viện và khi khám lại ở thời điểm 3 tháng sau phẫu thuật. Trong nhóm nghiên cứu của chúng tôi có $66,7 \%$ số bệnh nhân có cải thiện thị lực sau phẫu thuật, $45,5 \%$ tổng số bệnh nhân của nhóm nghiên cứu có cải thiện thị lực từ 2 dòng Snellen trở lên. Có $6,1 \%$ số bệnh nhân có thị lực giảm sau phẫu thuật 3 tháng và $27,3 \%$ nhóm nghiên cứu có thị lực không thay đổi. Theo những nghiên cứu trên thế giới, tỷ lệ thành công về thị lực (cải thiện từ 2 dòng trở lên) dao động từ $27 \%$ đến $100 \%$, với mức trung bình là $84 \%$. Nghiên cứu của Hou và Jiang trên 54 mắt bị lỗ hoàng điểm chấn thương cho kết quả với $89 \%$ số mắt có lỗ hoàng điểm đóng thành công sau phẫu thuật, thị lực của nhóm bệnh nhân được cải thiện đáng kế, $52 \%$ nhóm nghiên cứu có thị lực cuối cùng cải thiện trên 2 dòng. ${ }^{9}$ Tuy vậy Yuan và cs lại cho rằng không có sự cải thiện đáng kể chức năng thị giác ở 69,2\% trong số 26 trường hợp lỗ hoàng điểm đóng thành công sau phẫu thuật, tỉ lê tăng 2 dòng thi lực sau phẫu thuật chỉ có $27 \% .{ }^{5}$ Nguyên nhân của kết quả thị lực hạn chế được cho là do sự tổn hại của mối nối phần trong với phần ngoài của tế bào quang thụ, do hình thái đóng lỗ hoàng điểm type 2 và những thay đổi của lớp biểu mô sắc tố thứ phát sau chấn thương.

Trong nghiên cứu của chúng tôi, chiều dày trung tâm hoàng điểm sau phẫu thuật có xu hướng giảm so với trước phẫu thuật $(p=0,51)$, với chiều dày trung bình sau mổ là $171,61 \pm$ $78,73 \mu \mathrm{m}$. Nhóm bệnh nhân của chúng tôi có chiều dày trung tâm hoàng điểm sau phầu thuật mỏng hớn so với nghiên cứu của tác giả Tang trên các mắt có lỗ hoàng điểm đã được phẫu thuật với chiều dày trung bình là $232 \mu \mathrm{m} .{ }^{10}$ Điều này có thể được giải thích bởi chiều dày trung tâm hoàng điểm của một số bệnh nhân trong nghiên cứu của chúng tồi rất mỏng, có trường hợp mỏng nhất là $24 \mu \mathrm{m}$ khi đến viện và $39 \mu \mathrm{m}$ khi đến khám lại. Do chiều dày trung tâm hoàng điểm cũng được cân nhắc là một yếu tố liên quan thuận với mức đô phục hồi thị lực sau phẫu thuật của bệnh nhân lố hoàng điểm, nên chúng tôi thẩy rằng nhóm bệnh nhân của nghiên cứu có thể có tiên lượng về thị lực sau phẫu thuật khá là hạn chế.

Tổn hại mối nối phần trong-phần ngoài của các tế bào quang thụ hay còn gọi là vùng ellipsoid được coi là một yếu tố quan trọng cho tiên lượng thị lực sau điều trị. Nhóm bệnh nhân của chúng tôi có vùng ellipsoid giảm nhẹ khi so sánh trước và sau phẩu thuật $(2316,49 \mu \mathrm{m}$ so với 2156,63 m), không có ý nghĩa thống kê. Số liệu này trong nghiên cứu của tác giả Tang và cs là $2221 \mu \mathrm{m}$ trước điều trị và $1589 \mu \mathrm{m}$ sau điều trị, nhỏ hơn đáng kể so với nghiên cứu của chúng 
tôi. Tác giả Miller và cs trong quá trình theo dõi các mắt có lỗ hoàng điểm chấn thương cho nhận định rằng các mắt có thị lực cuối cùng tốt hơn là những mắt có vùng ellipsoid được bảo toàn nhiều hơn. ${ }^{4}$ Chúng tôi cũng quan sát thấy những trường hợp lỗ hoàng điểm đóng type 2 sau phẫu thuật thường đi kèm với vùng ellipsoid trước và sau phấu thuật khá lớn $(3043,25$ um so với $2617 \mu \mathrm{m}$ ). Điêu này cũng gợi ý cho chúng tôi tiên lượng về thị lực sau mổ khá kém của nhóm bệnh nhân nghiên cứu.

Chúng tôi cũng đánh giá kích thước đỉnh và đáy lố hoàng điểm trước và sau điều trị trong các trường hợp lỗ hoàng điểm đóng type 2 . Kết quả cho thây kích thước đỉnh lỗ hoàng điểm có xu hướng giảm tuy nhiên sự khác biệt không có ý nghĩa thống kê. Tuy nhiên kích thước đáy lỗ hoàng điểm trước và sau điêu trị giảm có ý nghĩa thống kê với $p<0.05$. Như vậy với những trường hợp đóng lỗ hoàng điểm type 2 sau phẩu thuật, chúng tôi thấy lỗ hoàng điểm trên OCT có thu hẹp về kích thước.

\section{KẾT LUẬN}

Lỗ hoàng điểm chấn thương là môt bênh cảnh nặng ảnh hưởng nghiêm trọng đến chức năng thị giác. Tỉ lệ đóng lỗ hoàng điểm chấn thương của nhóm nghiên cứu nói chung sau một đến hai phẫu thuật và tỉ lê thành công đóng iỗ hoàng điểm sau một lần phẫu thuật còn khá hạn chế. Gần một nửa nhóm nghiên cứu có thị lực cải thiện trên 2 dòng sau phẫu thuật 3 tháng. Chiều dày trung tâm hoàng điểm sau phẫu thuật có xu hướng giảm so với trước phẫu thuật. Vùng ellipsoid giảm nhẹ khi so sánh trước và sau phẫu thuật, không có ý nghĩa thống kê. Trung tâm hoàng điểm teo mỏng và vùng ellipsoid rộng sau phẫu thuật hướng đến một tiên lượng không tốt về hồi phục thị lực của nhóm bệnh nhân. So sánh giữa trước và sau phẫu thuật, kích thước đỉnh lố hoàng điểm có xu hướng giảm với sự khác biệt không có ý nghĩa thống kê, kích thước đáy lỗ hoàng điểm giảm có ý nghĩa thống kê.

\section{TÀI LIẸU THAM KHẢO}

1. Kelly NE, Wendel RT. Vitreous surgery for idiopathic macular holes: results of a pilot study. Archives of ophthalmology. 1991;109(5):654-659.

2. Amari F, Ogino $N$, Matsumura $M$, Negi A, Yoshimura N. Vitreous surgery for traumatic macular holes. Retina (Philadelphia, Pa). 1999;19(5):410-413.

3. Kang S, Ahn K, Ham D. Types of macular hole closure and their clinical implications. British Journal of Ophthalmology. 2003;87(8):1015-1019.

4. Miller JB, Yonekawa $Y$, Eliott $D$, et al. Longterm follow-up and outcomes in traumatic macular holes. American Journal of Ophthalmology. 2015;160(6):1255-1258. e1.

5. Yuan L, Han J, Xiaorong L. Clinical analysis of 47 cases with traumatic macular hole resulted from ocular contusion. Chinese Journal of Ocular Fundus Diseases. 2015;31(1):45-48.

6. Ghoraba HH, Ellakwa AF, Ghali AA. Long term result of silicone oil versus gas tamponade in the treatment of traumatic macular holes. Clinical ophthalmology (Auckland, NZ). 2012;6:49.

7. Miller JB, Yonekawa Y, Eliott D, Vavvas DG. A review of traumatic macular hole: diagnosis and treatment. International Ophthalmology Clinics. 2013;53(4):59-67.

8. Chen $\mathbf{H}-\mathbf{J}$, Jin $\mathbf{Y}$, Shen $\mathbf{L - J}$, et al. Traumatic macular hole study: a multicenter comparative study between immediate vitrectomy and sixmonth observation for spontaneous closure. Annals of translational medicine. 2019;7(23)

\section{PHÂN TÍCH CÁC YẾU TỐ LIÊN QUAN ĐẾN SÃN SÀNG CHI TRẢ CHO NộI SOI ĐẠI TRỰC TRÀNG ĐỂ SÀNG LỌC UNG THƯ ĐẠI TRỰC TRÀNG TẠI VIỆT NAM}

\section{TÓM TẮT}

Mục tiêu: Phân tích các yếu tố liên quan đến sẵn sàng chi trả (WTP) đối với xét nội soi đại trực tràng để sàng lọc ung thư đại trực tràng tại Việt Nam. Phương

*Trường Đại học Y tế Công cộng

Chịu trách nhiệm chính: Nguyễn Quỳnh Anh

Email: nqa@huph.edu.vn

Ngày nhận bài: 4.3.2021

Ngày phản biên khoa học: 28.4.2021

Ngày duyệt bài: 11.5.2021

\section{Nguyễn Quỳnh Anh*, Nguyễn Thu Hà*}

pháp: Sử dụng bộ số liệu trên 402 đối tượng 50-75 tuổi đến khám bệnh thông thường tại các phòng khám ngoại trú thuộc Trung tâm y tế quận Hoàn Kiếm từ tháng 1 đến tháng 3/2019. Phân tích mối liên quan bằng mô hình hồi quy đa biến phân tích mối liên quan giữa WTP với các biến số độc lâp (nhân khẩu - xã hô̂i học, yếu tố nguy cơ của ung thư đại trực tràng và kiến thức-thái độ về ung thư đại trực tràng). Kết quả và kết luận: Lựa chọn sẵn sàng chi trả đối với nội soi đại trực tràng được chỉ ra là có liên quan có ý nghĩa thống kê với thu nhập, tình trạng đang làm việc hiện tại, số thành viên trong hộ gia đình, người thẩn trực hệ trong gia đình có ít nhất một yếu tố nguy cơ với 